\title{
the \\ Humanitarian Leader
}

Community-led disaster resilience in Nauiyu Aboriginal community

\author{
ANNIE INGRAM
}

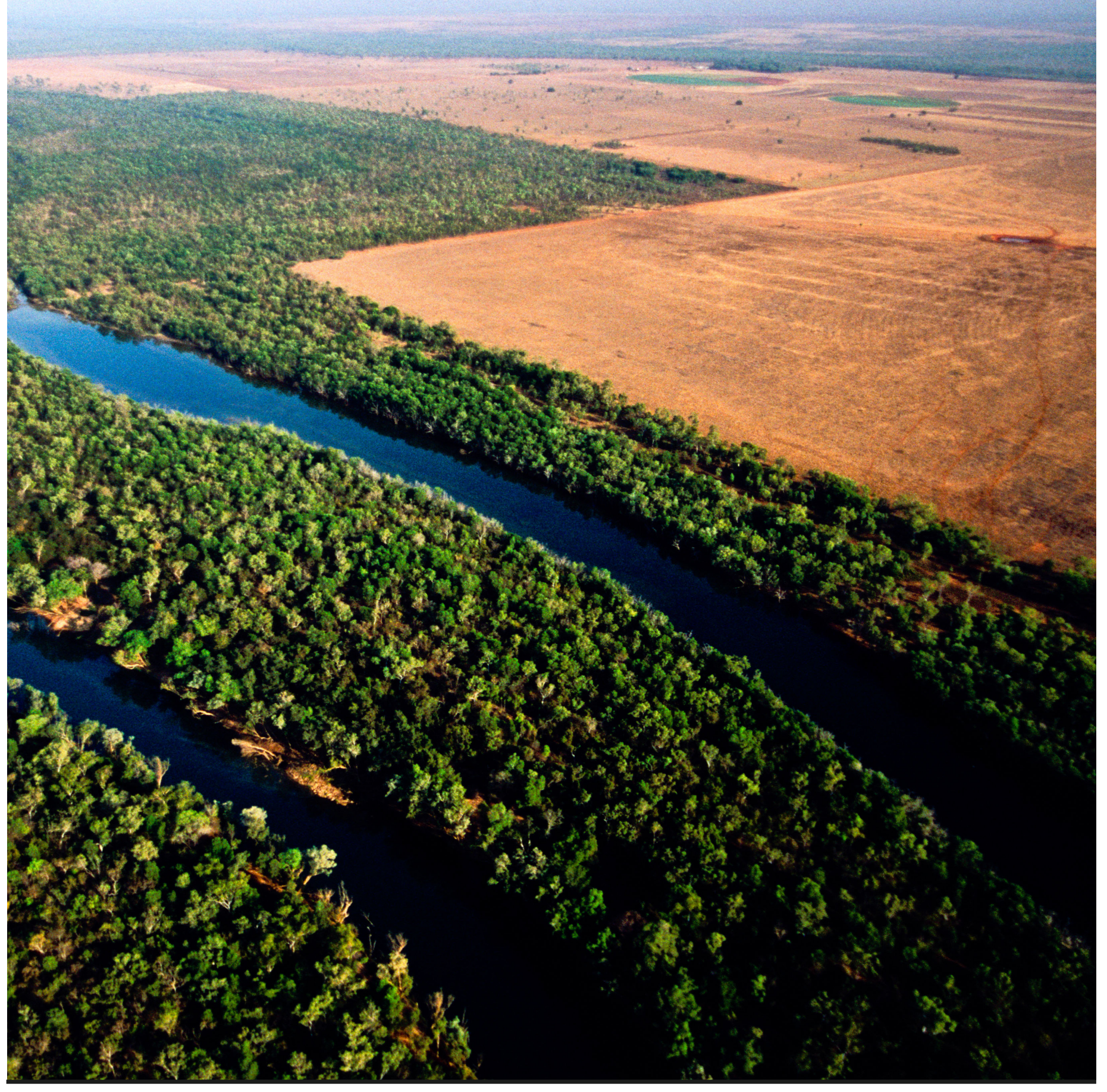




\title{
THE HUMANITARIAN LEADER: \\ Community-led disaster resilience in \\ Nauiyu Aboriginal community
}

\author{
WORKING PAPER 018
}

SEPTEMBER 2021

\section{Author Details}

\section{Annie Ingram}

Annie currently works for the United Nations Office for the Coordination of Humanitarian Affairs as an Accountability to Affected Populations and Community Engagement Specialist. She is a graduate of the Centre for Humanitarian Leadership, and has worked in Aboriginal communities, PNG, Indonesia, and Myanmar.

\section{Acknowledgements}

I am thankful to many for their support of this article. Phil Connors provided invaluable supervision and guidance in producing this research, and Australian Red Cross allowed me to explore these issues during my employment there. Mainly, I am indebted to the people of Nauiyu, who taught me so much about being Aboriginal in Australia, and of their experience in disasters specifically. Nauiyu Elder Miriam-Rose Ungumerr-Baumann is the star of this research and I can't thank her enough for her generosity in sharing her knowledge.

\section{Editorial Office}

The Centre For Humanitarian Leadership

Deakin University

221 Burwood Highway

Burwood 3125 VIC

Australia

Editor in Chief: Dr Nazanin Zadeh-Cummings

ISSN: 2653-1011 (Online)

The Humanitarian Leader is made possible by support from the IKEA foundation.

The Centre for Humanitarian Leadership acknowledges the Australian Aboriginal and Torres Strait Islander peoples of this nation. We acknowledge the traditional custodians of the lands on which we work. We pay our respects to ancestors and Elders, past and present.

\section{Copyright}

This paper was prepared for the Centre for Humanitarian Leadership. The views expressed herein are those of the authors and do not necessarily reflect the views of the Centre for Humanitarian Leadership. These papers are circulated for discussion and comment purposes. They have not been peer reviewed.

(C) 2021 by Annie Ingram. All rights reserved.

Cover image: An aerial view of the Daly River, Northern Territory, Australia @ Bill Bachman / Alamy Stock Photo. 


\section{Abstract}

There is a need for emergency management systems in Australia to shift to a more collaborative model that involves working with communities rather than simply delivering to communities. This research paper argues that in order to address this, emergency services organisations in Australia need to continue to shift from a service delivery approach to a more localised, participatory and consultative model that acknowledges and harnesses local leadership, knowledge, skills and experience creating opportunities for community driven and fit-for-purpose emergency management. The paper makes the case for why localised approaches are important in places with diverse populations such as the Northern Territory (NT). The NT Aboriginal community of Nauiyu's experience of evacuations due to flooding in 2015 and 2018 will be used as a case study to offer an example of locally led approaches to disaster resilience.

\section{Leadership relevance}

This paper offers insights into how leaders in emergency management in Australia can better serve the needs of remote Aboriginal communities. Leaders in emergency management throughout Australia often acknowledge they need to work better with Aboriginal people and communities, however many don't know where to start. This paper shares firsthand insight from Aboriginal people and those who have responded to emergencies affecting Aboriginal communities. Much of the literature on this topic doesn't offer potential solutions or link the Australian experience to the broader international humanitarian context. This paper seeks to do that, in order to offer emergency leaders in Australia a different perspective with practical examples. 


\section{Introduction}

The 2016 World Humanitarian Summit brought unprecedented commitment to and focus on localisation in the humanitarian sector. The resulting 'Grand Bargain' not only sets targets for financial reform in the humanitarian system but heralds a new way of working. It "envisions a level playing field where all meet as equals" (IASC 2016) and invites an era of working more collaboratively, respectfully and effectively with affected communities. Globally, the localisation agenda has already created shifts in the way humanitarian actors operate. While humanitarian organisations in Australia examine how to progress the localisation agenda in their work internationally, the ways humanitarian organisations work with communities in Australia must not be overlooked.

In Australia, it is widely recognised that remote Indigenous communities have become less resilient to disasters since colonisation (Paton \& Johnston 2017; 272). A range of factors, including limited resources, power imbalances, a lack of meaningful representation on decision making bodies, lack of access to emergency plans and a lack of ownership in planning for emergency management persists (Australian Red Cross 2018c). This research project argues that in order to address this, emergency services organisations in Australia need to continue to shift from a service delivery approach to a more localised, participatory and consultative model that acknowledges and harnesses local leadership, knowledge, skills and experience, creating opportunities for community driven and fit-for-purpose emergency management (Australian Red Cross 2018c; Australian Red Cross 2019; Ellemor 2005).

\section{Emergency services organisations in} Australia need to continue to shift...

to a more localised, participatory and consultative model that acknowledges and harnesses local leadership, knowledge, skills and experience.

This research project will first touch on the push for localisation throughout the humanitarian sector around the world and consider the extent to which localisation applies within Australia. Second, it will discuss why localised approaches are important in places with diverse populations such as the NT. It will then offer insights from disaster resilience work carried out by Australian Red Cross across three remote Aboriginal communities in the NT. Nauiyu community's experience of evacuations due to flooding in 2015 and 2018 will be used as a case study to offer an example of locally led approaches to disaster resilience.
How are Australian humanitarian organisations changing the way they work abroad? And does that apply in Australia?

Australian Red Cross has traditionally worked internationally and in Australia. The 'Grand Bargain' has led to Australian Red Cross reviewing its role internationally. In October 2017, research examining the role of Australian Red Cross in the Pacific titled Going local: Achieving a more appropriate and fit-forpurpose humanitarian eco-system in the Pacific was released. This report has been the catalyst for serious structural change within Australian Red Cross, leading to fundamental shifts in how Australian Red Cross manages international programs and supports Red Cross National Societies in the Pacific. Other major actors in the humanitarian sector in Australia have also followed suit in rethinking their role internationally and how the localisation agenda can be progressed. This has included Oxfam Australia (Oxfam Australia 2017a; Oxfam Australia 2017b; Oxfam Australia 2018), Save the Children (Save the Children 2019) and CARE Australia (Lehoux 2016).

The Going Local research posed the definition of localisation as follows:

lo.cal.is.a.tion (n.); is a process of recognising, respecting and strengthening the independence of leadership and decision making by national actors in humanitarian action, in order to better address the needs of affected populations (Ayobi et al 2017; 1).

It is important to note that while localisation has a financial component-the commitment to channel $25 \%$ of financing through local organisations by 2020-it encompasses far more than finance. Speaking at the 2019 Asia Pacific Humanitarian Leadership Conference, Adeso CEO Degan Ali said in her keynote speech that, "everyone thinks that localisation is just about money. It's not about money. It's about shifting power." Australian Red Cross describes implementing these shifts as follows: "The push is to work across the humanitarian/development nexus, and collaboratively across the sector, to leverage a bigger change than we could achieve on our own, and allow local actors to lead at every turn." (Ayobi et al 2017; 1).

"Everyone thinks that localisation is just about money. It's not about money. It's about shifting power."-Degan Ali

While it is clear that there are important shifts occurring in the way that Australian humanitarian organisations work internationally, it is less clear whether this same consideration is being given to Australian operations. The very definition of localisation above, with its focus on 'national actors', implies that it is something inherently international. What does this mean where power imbalances or historical disadvantage 
exist within a country? The structural inequalities that exist between Australia's Indigenous and nonIndigenous population are well documented. A history of colonialism, institutional racism, dispossession and forced disconnection with culture and language have all contributed to creating these enduring structural inequalities. While empowering communities and addressing structural inequalities may be spoken about using different language and terms in Australia, and not necessarily considered 'localisation' within countries, this global push for localisation may provide additional impetus at home too.

\section{How might aspects of localisation apply within Australia and how are community- led approaches fostered here?}

In 2018, I had the opportunity to work on a disaster resilience project with Australian Red Cross in the NT called Reimagining Resilience. The project aimed to explore ways to increase disaster resilience in remote Aboriginal communities through community-led approaches and ways of working that elevated and acknowledged Indigenous knowledge and leadership (Australian Red Cross 2018c). Australian Red Cross had received financing from the Department of the Chief Minister's NT Risk Priority Project Fund to implement the Reimagining Resilience project. The project sought to examine ways of strengthening remote Aboriginal community resilience in three key areas:

1. Harnessing existing traditional Indigenous knowledge to strengthen emergency management

2. Creating avenues for community-led emergency management and Indigenous representation

3. Contributing to systemic change in the emergency management sector.

The project focused on three communities prone to natural hazards across the Top End (generally considered to be the geographical area of the NT from the township of Katherine northwards), which were selected because Australian Red Cross had an existing presence and relationships within the communities. Activities for this project were then determined by each community in consultation with Red Cross. The three project sites were Pirlangimpi on the Tiwi Islands' Melville Island, Galiwin'ku on north-east Arnhem Land's Elcho Island and Nauiyu Community in Daly River.

Below is an overview of the focus in each:

\section{Pirlangimpi, Tiwi lslands}

- Focus: Art and traditional knowledge in supporting remote community resilience

- Partner: Munupi Arts.

\section{Galiwin'ku, Elcho Island}

- Focus: Governance and Yolngu authority and control in emergencies.

- Partner: Northern Australia Land and Sea Management Authority (NAILSMA).
Nauiyu, Daly River

- Focus: Cultural awareness in emergency workers

- Partner: Miriam-Rose Foundation.

I began working on the Reimagining Resilience project having recently moved to the NT from Indonesia via Adelaide. I had until then worked in roles in the international development sector in Australia, Papua New Guinea and Indonesia. I was also nearing the end of the Masters of Humanitarian Assistance, so until that point I had been very focused on the international context. I was excited by the opportunity to move to the NT and see how this work translated in an Australian setting.

In coming into this new space, it struck me that there were many similarities in the ways practitioners talked about working with communities around disasters in the international and domestic context, but also many differences in understandings and terminology. In particular, there were two key concepts from the international context that frequently came through in discussions about challenges within Australia. The first was around localisation and shifting power to affected communities (Australian Red Cross 2019). The second was around the 'humanitarian-development nexus' and how emergency and development actors were better able to serve the needs of affected communities together (Australian Red Cross 2019). A key difference that I encountered in transitioning from an international to a domestic context was the tight legislation that exists around emergency management in Australia and the 'command and control' culture of the sector (AFAC 2017; Australian Red Cross 2019). It begs the question of how easy or possible it is for voices of affected communities to be heard or for community leadership in emergencies to be nurtured in this environment.

\section{Why are different, localised responses needed in remote Aboriginal communities in the NT?}

The NT is a particularly relevant region in which to explore the idea of localisation in the Australian context, as well as the importance of community-led approaches in emergency management. Demographically, geographically and linguistically, the NT is distinct from the rest of Australia (ABS 2016), and it has a complex disaster risk profile (ABC 2019). As a wide expanse of land spanning from the tropical northern islands to the arid central desert, the NT experiences a range of natural hazards. Given its proximity to Asia, the NT has also played a key role in emergencies in the region, such as receiving evacuated people from from terrorist bombings that occurred in Bali, Indonesia, in 2002 and 2005 (Parry 2012) and being a staging site for emergency medical treatment in those disasters (Palmer et al 2003) as well as receiving evacuees from Timor-Leste in the early 2000s during the fight for independence (McDowell 2006; ABC 2006). It is now host to the National Critical Care and Trauma Response Centre, which is responsible for Australian Medical Assistance Teams (AUSMAT) that can rapidly deploy to international emergencies in the region (DFAT 2017). 
Demographically, geographically and rest of Australia linguistically, the NT is distinct from the

(like Mount Isa or Bourke), is very different to living in a remote area of the NT such as Galiwin'ku or Borroloola. These are communities of under 3,000 people, made up almost entirely of Aboriginal people who have kinship ties to one another, live on their traditional lands a considerable distance from any urban hub, and primarily speak languages other than English.

\section{Linguistic diversity in the NT}

The NT is also home to vast linguistic diversity-both among its Indigenous people and its diverse migrant population. In terms of Indigenous languages, the Top End is also equal second highest in the country in terms of the number of Indigenous languages spoken (ABS 2017a). According to the 2016 census, the Top End is home to more speakers of Indigenous languages than any other region of Australia (ABS 2017a). This area of the NT is also considered to be one of the most vulnerable to natural hazards and climate change so linguistic barriers must be a key consideration in emergency planning (ABC 2019; Bardon 2019). on 24-26 December, 1974), and the only Australian capital city to have been bombed as an act of war (WW2Japanese bombing of Darwin on 19 February, 1942) (Rechniewski 2012). The below section outlines the key areas in which the demography of the NT differs from the rest of Australia.

\section{Aboriginal people as a percentage of the \\ NT population}

While the NT does not have the highest number of Aboriginal people, despite what many people believe (this is in fact attributed to New South Wales), the NT has by far the highest proportion of Aboriginal people as a percentage of the population (ABS 2017b; ABS 2019). Whereas Indigenous people make up $2.8 \%$ of the overall Australian population, Indigenous people make up 25.5\% of the NT population (ABS 2017b). This data comes from the last Australian census carried out by the Australian Bureau of Statistics, however it is often estimated that the Indigenous population in the NT is greater than $25.5 \%$. Difficulty in reaching remote areas, transience of Indigenous people and linguistic, cultural and technological barriers to carrying out the census are possible reasons for this. The NT Government estimates Aboriginal people make up $30.3 \%$ of the population (NT Government 2019).

Percentage of Indigenous people living in rural or remote locations

Likewise, where Indigenous people live in the NT differs significantly to the location of other Indigenous people nationally. The census showed that around Australia, 20.4\% of Indigenous people lived in a "rural or remote area" (ABS 2017a). In the NT however, the census indicated that $48.8 \%$ of Indigenous people lived in a "rural or remote area" (ABC 2017). The jump from $20.4 \%$ of the population to $48.8 \%$ of the population is already stark, but consider this: what do we consider a rural or remote area around Australia? Queensland and New South Wales are the most regionalised states in Australia. But living in a rural hub in one of these states

\section{The importance of recognising diversity and empowering communities in emergency management}

It is clear from the ABS statistics that the NT is comprised of a population that is markedly different to that of the rest of Australia. However, many of Australia's emergency management systems and legislation are developed in and for Australia's major population centres. These systems often do not translate to the needs of remote Aboriginal communities or are not appropriate for the circumstances. The immense diversity that exists among Australia's First Nations people means that recognising, valuing and empowering community voices and leadership is crucial to getting emergency management right in such different contexts.

Disempowerment of affected communities in emergencies is not unique to remote Aboriginal communities-but structural inequality and historical disadvantage add additional complexities. Given its unique demographic and geography, and historical power imbalances, the NT provides a stark example. However, feelings of disempowerment when local voices and leadership are overlooked or ignored are indeed not unique to the NT or to Aboriginal communities.

The below quote, for example, refers to the experience of communities affected by the 2009 Black disempowerment and undervaluing of local knowledge, existing governance and structures.

The locals found that their initiative and drive in the early days was smothered by a recovery process described as overlooking local knowledge and expertise in community leadership. It further disadvantaged those locals with construction Saturday bushfires, but illustrates the same sense of 
equipment and skills, and men and women needing help with disaster-affected businesses. The overall effect was disempowering, and contradicted the appearance of meaningful community consultation (Zara and Parkinson 2013).

No matter the composition of the affected population, the way emergency responders treat people affected by disasters is important in their psychosocial recovery (Australian Red Cross 2010). Disaster management systems that do not place affected people at the centre of operations have the potential to do a great disservice to the people they are trying to help. In some instances, the response can cause greater damage than the emergency event itself. However, given the cultural, linguistic, geographic, historical and structural factors in the NT, the matter is even more complex when dealing with remote Aboriginal communities.

\section{Case study: Nauiyu Community, Daly River Region, NT}

The Reimagining Resilience project was brought about as a result of difficult past emergencies where the emergency services sector could have managed emergency responses and recovery affecting Aboriginal land and Aboriginal communities much better. Tropical Cyclones Nathan and Lam, which ravaged north-east Arnhem Land in February and March 2015, were consistently offered as examples of where local people had been disenfranchised in the relief and recovery efforts. Many Yolngu at Galiwin'ku who were affected by these cyclones refer to what came after the cyclones as "the real disaster," with external agencies operating without true deference to local authorities and governance structures and thereby creating a sense of disenfranchisement among the local population (Gondarra 2019).

In taking on this project, it seemed everyone I spoke with had stories they wanted to share about examples of where emergency actors had gone wrong in Aboriginal communities. Nauiyu stuck out as the community where people wanted to talk about examples of getting it right. There were also stories of struggles and mistakes, but there was a positivity in the way people spoke about Nauiyu in terms of how much had been learned, and how far everyone (the community and emergency sector) had come in responding to flooding in that community. Starting in this project I felt as though I was hearing constant stories of where the sector was getting it wrong, or at least was perceived to be. I was very interested to learn anything I could about the factors that contributed to getting it right.

Nauiyu is a small Aboriginal community situated on the banks of the Daly River which is vulnerable to flooding. The community is home to approximately 450 residents from 14 main family groups. There is a small air strip in the community, but access to the community is most commonly via long stretches of narrow, windy roads. The drive there takes approximately 2.5 hours from Darwin or 3 hours from Katherine. When the community floods, the community members are evacuated to Darwin and accommodated at Foskey Pavilion at the Darwin Showgrounds as per the Territory Emergency Plan (NT Government 2019). Nauiyu was originally established as a Catholic mission, and to this day the Catholic church located in the centre of the community is a prominent feature in community life. On the country surrounding the community, there are many sacred sites and places of cultural significance. The scenery around Daly River is tranquil, but the presence of a site called Blackfella Creek where an estimated 150 Aboriginal people were killed in the 1884 Woolwonga Massacre is a reminder that the history of this region has not always been so peaceful (Lindsay 2013; The South Australian Register 1886; Allam \& Evershed 2019).

The two most recent evacuations took place in December 2015 and January 2018, spanning 15 days and 18 days respectively (Australian Red Cross 2015; Australian Red Cross 2018b). Under NT emergency arrangements, Territory Families is the government department responsible for leading the NT's Welfare Group and therefore responsible for evacuation centres (NT Government 2019). Australian Red Cross is a member of the Welfare Group and, since the 2015 Nauiyu evacuation, has had an arrangement with Territory Families for the management of evacuation centres (Australian Red Cross 2016; Australian Red Cross 2018a). In the 2015 evacuation, Territory Families managed the evacuation centre for the first four days as was the arrangement at the time, before asking Australian Red Cross to take over (Australian Red Cross 2016). An evacuation centre management contract has been in place ever since for Australian Red Cross to manage evacuation centres in the NT (Australian Red Cross 2019). Australian Red Cross has had a full-time staff member based in the community since 2013 who, along with carrying out other community development work, has assisted in emergency preparedness, response and recovery (Mitchell 2019a).

The relationship between this community and emergency agencies, as well as the community's preparedness for emergencies, have evolved over time. Feedback from the community was that the 2018 evacuation was far better than the 2015 evacuation. The following will discuss why that may have been the case and the key components of this progression that may be able to be applied or built upon in working with other Aboriginal communities around emergencies. The Reimagining Resilience project, interested in identifying factors that influenced this improvement, sought to better understand the community's experience with those two recent evacuations.

Throughout the course of the project, I was able to have many conversations with community members, emergency workers who had been involved in the floods, service providers based in the community, Red Cross workers involved with the community and the flooding, and government workers involved in emergency planning, about their perspectives on what was learned and improved on during the recent floods. The responses fell into three main categories. 
1. A relationship focus

2. Community representation

3. Continuity of relationship and learning.

The following passage uses interviews with a community worker and a community Elder to delve into why these three areas have been important in improving Nauiyu community's experience of emergency evacuations between 2015 and 2018. It draws heavily from an interview with Miriam-Rose Ungunmerr-Baumann, an Elder from Nauiyu, in which she shares her community's experience with flood emergencies. It also draws from a report and case study series released by the Social Recovery Reference Group in which Red Cross facilitated the documentation of the experience in the NT of the two recent Nauiyu evacuations.

\section{A relationship focus-learning from each other, learning how to be with each other}

The Reimagining Resilience project highlighted the importance of relationships between communities and emergency agencies in enabling communityled response. It is important to build these trusted relationships over time, well in advance of a disaster event (Aldrich 2018). It can be said that a factor in the improvement of evacuations between 2015 and 2018 is the work that has been done in building relationships in the community outside of emergency times (Mitchell 2019b). Red Cross has had a presence in Nauiyu Community since 2013. The sustained relationship between Red Cross and the community has assisted in building mutual understanding, collaboration and decision making around recent evacuations. Maddy Bourke has been a community development officer with Red Cross since 2015. Of building relationships with the community, she says:

I have over this period built up the trust of the community Elders and as a result been able to effect change in the way community responds to situations of emergency and great sorrow or stress ... Trust is built from the community getting to know you and know they can rely on you in both the good and the bad times. I have tremendous respect for the community and their resilience in times of adversity. As a result of this I was included in many of the decision-making committees and was relied upon to help in many various situations. I was also able to establish a good rapport with the young people of the community, gaining their trust over the years I have been there (Mitchell 2019a; 33).

Interested to know about the community's perspective on this, I had a conversation with Community Elder Miriam-Rose Ungunmerr-Baumann about how she saw the development of the relationship between the 2015 and 2018 floods. As a retired teacher and school principal-and an eternal educator-it was no surprise that she identified a "learning mindset" as central to the development of relational trust.
Rather than viewing the relationship as fixed and unchanging, Miriam views it as a "process". She often refers to a "process of learning from each other" or a "process of learning to be with each other". This is her perspective on both the community and emergency services agencies learning how to work together, and the community, in its diversity, learning how to be with each other in a very different setting to what they are used to (Mitchell 2019a).

I asked Miriam how she thought the relationship between Nauiyu community and the emergency services sector, particularly those agencies involved in the community members' stay in the evacuation centre in Darwin, had changed.

The first time we went out [2015] we were all in learning mode in how to deal with each other.

I think there was that thing of them not knowing how to do things with us and us not knowing what their expectation was I think that brought it to a head (a live and learn thing); it was picked up and noted when we were there the first time.

It made it feel better for the second time because we know at least if we were going there again at least they have a little bit of an understanding of how we are going to react, you know, towards each other (Mitchell 2019a; 34).

I asked if there were any things specifically put in place that led to these sorts of changes. Miriam explained that a lot of listening to the community had been done about what needed to happen in future. There was the appointment of the two community representatives for emergencies-Miriam-Rose and Mark Casey-which she explains was key in 2018. There was also the community design of an evacuation centre plan, so that if the community members were to be evacuated again, the evacuation centre could be set up in a way that suited them. This was able to be used in 2018. Miriam reflected that with all of this, issues were more easily identified and addressed in the evacuation centre in 2018:

There was things I suppose put in place from the previous time we'd been with you. Listening to uswhat it was-two people [community leaders MiriamRose and Mark] that was there-that is happening, this is happening, this has to be corrected somehow... just little things like that that we brought to their attention (Mitchell 2019a; 34).

With the impacts of climate change already being felt by Nauiyu Community, Miriam-Rose is realistic about the likelihood of needing to be evacuated due to flooding again in the coming years. However, she is also optimistic about what will happen should the unfortunate arise.

This is happening one many times too many because of the climate and stuff and we've got to go with the flow and learn and be good with each other and just with our people too that run amok (Mitchell 2019a; 34). 
Nature's funny and she does things in her own way, and if there was going to be a time when we've got to come again to be with you, [I] think that would be almost even better than the last time (Mitchell 2019a; 35).

Following the evacuation in 2018, Red Cross emergency services workers who were involved in the evacuation were invited to travel to Nauiyu for a Water Blessing in the river that had flooded. This was the community's way of offering thanks. The ceremony includes putting water on the head and the navel to symbolise coming into the world in infancy. The ceremony connects the people being blessed to that country and welcomes them as part of that place. The community also invited emergency services workers from various agencies to come and spend a week in their community to experience life in community and learn about country and culture. The workshop was suggested after the community was asked what it wanted to do with money earmarked for 'community resilience' and opted to educate the sector rather than the other way around, which was symbolic of where the relationship was between agencies and the community.

\section{Community representation}

Another key element that was identified as improving between the 2015 and 2018 evacuations was community representation in preparing for, responding to and recovering from disasters. Nauiyu provides an example of how community can influence and be involved before, during and after disasters. While the importance of community representation and voice in emergency response is somewhat embedded into the emergency response psyche in the NT, particularly around evacuations, sustained involvement of community leaders is less common in other parts of the disaster management project cycle. There have certainly been examples in the NT where community representation has not been adequate but embedding community representation in emergency response has come a long way in the past few years and the sector continues to try to build on this (Australian Red Cross 2018c; Mitchell 2019b; Ellemor 2005). Nauiyu offers an example of how community members have been involved in preparedness, response and recovery, partly due to the sustained Red Cross emergency work in the community over the course of many years.

During the 2015 evacuation, a need was identified for people to speak for the community in a consolidated voice in order to represent the requirements of the community. There was a need for liaison of sorts between community and emergency agencies. Two Community Elders, Miriam-Rose and Mark, took on this role as it was seen to be important to have a male and female representative and that these people be from different family groups. These two would be the primary representatives, and representatives of other language groups or families would join or be consulted with as needed.
Miriam-Rose explained that she and Mark are very different people, but they complemented each other well. Of her relationship with Mark, she says:

We get on like wildfire, he speaks my mother's language, he [has a] police background, me teaching background. He can be really, really heavy with people playing up. It's good-we've got different ways of talking to people... whether there's kids or adults (Mitchell 2019a; 35).

She explained that they became the representatives in the evacuation centre during the 2015 evacuation, and the same approach was used again in the 2018 evacuation. The reasoning for this eventuating was described as follows:

They [the people running the evacuation centre] were having problems with us in finding one or two spokespeople for the group. I suppose almost 500 people and they couldn't spread themselves out to go individually to speak to all the people there and so decided to have two people to talk to (Mitchell 2019a; 36).

Also wanted to make it into something to use in the future, me and another person, also get other Elders from other language groups. Sometimes it was just the two of us and sometimes they/we got the other language groups to come in, so we'd have sessions in the centre, as often as (Mitchell 2019a; 36).

Miriam said their role was to "talk, update on things that were happening and if there were any things that the Elders wanted to update agencies on, that was their opportunity" (Mitchell 2019a; 36). In addition to these meetings with the Elders, there would also be a whole of community meeting in the evacuation centre each day.

While both sides-community and emergency services agencies-have seen the community representation as very important, Miriam-Rose reflects that it can be a challenging role.

... you've got the community coming to you and all the agencies as well... sometimes that's an issue with me personally and I just get away from inside the pavilion and go and sit in the kitchen area. It's not just our mob, it's people from that side too, government mob, or other offices or businesses (Mitchell 2019a; 36).

While it can be a difficult role, it is important to note that Miriam-Rose was offered accommodation outside of the evacuation centre by a charity she is affiliated with and turned down the offer. She said it was important she stay in the evacuation centre with her community and carry out this important role, even though it meant little reprieve for her personally. Of the offer to stay offsite Miriam said she was thankful, but she wanted to be there at the evacuation centre, "just in case something happens and that you're not understanding what the needs are in the people as we go through this process of learning from each other" (Mitchell 2019a; 34). 
When the community was evacuated in 2018 , there were clearer expectations all round and lots of lessons learned from the previous evacuation three years before. In 2018, the community representatives were able to establish the cultural expectations of people in the community for staying in the evacuation centre:

... when we went the second time, I think the people had got the message because we'd talked to them too and said, 'Hey, look we're not here for a party, we're here because we've got issues at home with water and stuff and these people are trying to look after us and make sure that we're comfortable' (Mitchell 2019a; 37).

It is important to have a coordinated approach from the agency side when approaching this community interface model. Firstly, as Miriam identified, it can be very taxing on the community representatives. Secondly, the community is likely to make little distinction between which agency is which and where different people they talk to in the centre are from. When community members at Nauiyu talk about their experience of being evacuated, the terms 'your mob' and 'my mob' are used when talking about the community and the agencies involved (Mitchell 2019a). In referring to all agencies as 'your mob', there is no distinction between the different parties involved whether it be government agencies, non-government organisations or other groups. This emphasises the importance of seamless coordination and communication between different agencies involved at this community interface (Mitchell 2019b). While agencies may have different mandates among themselves and tensions with other agencies, it is important that all agencies coordinate well to facilitate smoother experiences for the community.

\section{Continuity of relationship and learning}

None of this work is possible overnight and continual two-way learning through relationship building is needed over time. There is a requirement for sustained work outside of emergency responses to build on relationships and what has been learned. Meaningful partnership means two-way learning and respect; communities that are resilient and prepared for emergencies, and an emergency services workforce that is equipped to work with communities in culturally appropriate ways and to adapt to meet the needs of diverse populations.

Recognising this, Australian Red Cross and the MiriamRose Foundation ran cultural awareness workshops in Nauiyu in December 2018 and June 2019 for twenty emergency services workers. In the workshop, the community emphasised the importance of activities such as these and "slowly, slowly, learning to walk together in that comfortable walk" (Ungunmerr-Baumann 2019). While running the workshops, Miriam-Rose encouraged agency personnel, whether volunteer or paid, to keep coming back to deepen relationships and knowledge of their culture and country, remarking "it's not overnight we're going to get to know each other."
In the interview with Miriam-Rose, the importance of relationships and the difficulty of the inevitable turnover of staff in emergency agencies was discussed. It was noted that there was no expectation that things would remain continuous, rather a compassionate recognition that "you have to have a rest and go be with your mob." The impact of this relational trust was significant in terms of what the Nauiyu community leaders can expect and what they know is expected of them (Mitchell 2019a; 38).

Miriam-Rose touched on what it was like for her in the evacuation centre dealing with lots of different staff from different agencies:

... then another person comes in and there are changeovers in the place at times, and we go looking for somebody and then they say 'this one's here in their place' and you're dealing with another new person that you're not familiar with ... sometimes that's hard, 'should I or shouldn't I, or should I just leave it?' A lot of the time it's not really serious stuff, but thinking, 'Oh how do we do this, change that, or how do the people do whatever it is that's happening here?' And sometimes I'm standing off because I don't know that person well-the people that I've now met, they've been exposed to us and we've found what is expected of us (Mitchell 2019a; 38).

In order to work in culturally sensitive ways with communities, emergency services workers and agencies need to be aware of their own cultural values and how this may influence their work with community members. It is said that "the dominant cultural values of the organisations, agencies and partners working with communities will influence their perceptions of the community's capacity to be involved in decision making" (Mitchell 2019b; 57). It is often believed there are nine dimensions that underlie cultural similarity and difference in regard to cultural norms or values. The most relevant of these in the context of how the emergency sector can support community-led recovery is "societal individualism through to collectivism" (Mitchell 2019b; 57). Mitchell (2019b, 57) states that "this was evident in the Nauiyu Evacuation Centre where there was a respect for the values of the community demonstrated through the relational emphasis and the group goals that government and community were working towards."

A lot of work has been done in building relationships and creating more equal partnership models between community and emergency services agencies. The challenge now will be going one step further and better using Indigenous knowledge in mainstream emergency management. During the cultural workshops, Miriam spoke about learning how to navigate the cultural systems of mainstream Australia, particularly as a young teacher and in her dealings with government agencies in Darwin. She said she had needed to learn how to dress and how to talk in that particular environment. She told the group, "We have to learn how to be in your world, and now by coming here you can choose to learn how to be in our world" (Ungunmerr-Baumann 2019). 


\section{Conclusion}

This research project has sought to highlight the diversity that exists in Australia and among our First Nations People and explore why localised emergency management approaches are important as a result. Emergency management systems in Australia are making efforts to shift to a more collaborative model that involves working with communities rather than simply delivering to communities. There is, however, still work to be done to shift from a service delivery approach to a more localised, participatory and consultative model that acknowledges and harnesses local knowledge and creates opportunities for community driven and fit-forpurpose emergency management for all Australians.

There is great promise in the appetite for change and reform in the localisation space in the global humanitarian landscape. When it comes to localisation, in carrying out these much-welcomed reforms globally, the sector mustn't overlook the opportunity to redress the power imbalances and lack of representation in emergencies that exist within Australia, particularly in some of our most vulnerable communities.
The localisation agenda provides an impetus to review power imbalances throughout the global humanitarian system, and those that exist within Australia should not be exempt.

As the interview with Nauiyu Community Elder Miriam-Rose shows, when there is a focus on strong relationships, continuous learning and community representation, the experience of an emergency can be much less stressful for affected people. It reinforced the importance of the emergency management sector in Australia valuing and acknowledging existing capacities and governance systems that exist within communities. The localisation agenda provides an impetus to review power imbalances throughout the global humanitarian system, and those that exist within Australia should not be exempt. 


\section{References}

Ali, D. (2019, May 22-24). Keynote Speech, Asia Pacific Humanitarian Leadership Conference, Melbourne

Allam, L, Evershed, N. (2019, March 4). The killing time: the massacres of Aboriginal people Australia must confront. The Guardian Australia https://www.theguardian.com/australia-news/2019/mar/04/the-killing-times-the-massacres-ofaboriginal-people-australia-must-confront

Australasian Fire and Emergency Services Authorities Council. (2017). The Australasian Inter-Service Incident Management System. AFAC Ltd

Australian Broadcasting Corporation. (2006, May 28). Timor evacuees land in Darwin. https://www.abc.net.au/ news/2006-05-28/timor-evacuees-land-in-darwin/1764146

Australian Broadcasting Corporation. (2019, October 14). The Top End is on the front line of Australia's most severe climate challenges. ABC News. https://www.abc.net.au/news/2019-10-14/the-top-end-and-climatechange/11599036?nw=0

Australian Bureau of Statistics. (2017a). Aboriginal and Torres Strait Islander Population, 2016. 2071.0-Census of Population and Housing: Reflecting Australia-Stories from the Census. https://www.abs.gov.au/ausstats/abs@.nsf/ Lookup/by\%2OSubject/2071.0 2016 Main\%2OFeatures Aboriginal\%2Oand\%2OTorres\%2OStrait\%2Oislander\%20 Population\%20Article 12

-(2017b) Census: Aboriginal and Torres Strait Is/ander Population. https://www.abs.gov.au/ausstats/abs@.nsf/ MediaRealesesByCatalogue/O2D50FAA9987D6B7CA25814800087E03

Australian Bureau of Statistics. (2019). 2016 Census: Aboriginal and/or Torres Strait Is/ander Peoples QuickStats. https:// quickstats.censusdata.abs.gov.au/census_services/getproduct/census/2016/quickstat/IQSO36

Australian Red Cross. (2010). Communicating in Recovery. https://www.redcross.org.au/getmedia/2810a05a-3327-47f48a2a-7e89c14e2335/Communicating-in-recovery-resource.pdf.aspx

Australian Red Cross. (2016) After Action Review: Daly River Flood 2015. [Unpublished internal document]

Australian Red Cross. (2018a). 2017-18 Brief Event Summary. [Unpublished internal document]

-(2018b). Key Stats 2017-18 Activations. [Unpublished internal document]

-(2018c). NT Risk Priority Fund Grant Application. [Unpublished internal document]

Australian Red Cross. (2019). Reimagining Resilience Final Report. [Unpublished internal document]

Ayobi, Y., Black, A., Kenni, L., Nakabea, Sutton, K. (2017). Going Local: Achieving a more appropriate and fit-for-purpose humanitarian eco-system in the Pacific. Australian Red Cross. https://www.redcross.org.au/getmedia/fa37f8eb-51e74ecd-ba2f-d1587574d6d5/ARC-Localisation-report-Electronic-301017.pdf.aspx

Bardon, J. (2019, October 14). NT traditional owners urge climate change policy makers to witness mangrove devastation. $A B C$ News. https://www.abc.net.au/news/2019-10-14/climate-change-mangrove-traditional-owners-call-foraction/11598238

Cornish, L. (2019). Q\&A: Degan Ali on the systemic racism impacting humanitarian responses. Devex. https://www.devex. $\mathrm{com} /$ news/q-a-degan-ali-on-the-systemic-racism-impacting-humanitarian-responses-95083

Department of Foreign Affairs and Trade. (2017). Australian Medical Assistance Teams. https://www.dfat.gov.au/aid/ topics/investment-priorities/building-resilience/humanitarian-policy-and-partnerships/Pages/australian-medicalassistance-teams-ausmat

Ellemor, H. (2005) Reconsidering emergency management and Indigenous communities in Australia. Global Environmental Change Part B: Environmental Hazards. 6(1), 1-7. DOI: 10.1016/j.hazards.2004.08.001

Green, D., Jackson, S. \& Morrison, J. [Eds] (2009). Risks from Climate Change to Indigenous Communities in the Tropical North of Australia. Australian Government Department of Climate Change and Energy Efficiency. http://web.science. unsw.edu.au

Gondarra, T. (2019, April 2) Bushfire and Natural Hazard CRC Research Advisory Forum, Charles Darwin University Inter-Agency Standing Committee. (2016) What is the Grand Bargain? https://interagencystandingcommittee.org/ frequently-asked-questions-faqs-grand-bargain

Jones, A. (2019, November 24). Climate change affecting diversity in some of Australia's most remote areas, despite work of Indigenous rangers. ABC Science. https://www.abc.net.au/news/science/2019-11-24/karajarri-indigenous-rangersconservation-extinction-climate/11672856

Lehoux, F. (2016). Localisation in Practice: A Pacific Case Study. Care and Live and Learn Fiji. https://www.care.org.au/ wp-content/uploads/2016/10/Localisation-Case-Study-October-2016-13.10.pdf

Lindsay, G. K. (2013). Murder at the copper mine and beyond: the copper mine murders in 1884 near Daly River in the NT. Historical Society of the NT

McDowell, C. (2006). Displacement, return, and justice in the creation of Timor Leste. In Nicholas Van Hear and Christopher McDowell (Eds.), Catching Fire: Containing Forced Migration in a Volatile World (pp.181-211). Lexington Books 
Mitchell, L. (2019a). Case studies exploring community-led recovery and coordination, Social Recovery Reference Group, Melbourne. https://knowledge.aidr.org.au/media/7351/case-studies-exploring-community-led-recovery-andcoordination-final.pdf

- (2019b). Considerations for governments supporting community-led recovery, Social Recovery Reference Group, Melbourne. https://knowledge.aidr.org.au/media/7349/considerations-for-governments-supporting-community-ledrecovery-final.pdf

Mitchell, T. (2019). Visions and Violence of Policy: An ethnography of Indigenous Affairs bureaucratic reform in the NT, University of Sydney. https://ses.library.usyd.edu.au/bitstream/handle/2123/20510/michel_t_thesis.pdf?sequence=1

NT Government. (2019) NT Economy-Population. https://nteconomy.nt.gov.au/population

NT Government. (2019) Territory Emergency Plan https://pfes.nt.gov.au/sites/default/files/uploads/files/2019/TEP\%20 April\%202019.pdf

Oxfam Australia. (2017a). 2017-18 Pre-Budget Submission. https://treasury.gov.au/sites/default/files/2019-03/C2016052_Oxfam-Australia.pdf

- (2017b). The Future of Australian Aid: A blueprint for an aid program that delivers on the Sustainable Development Goals. https://www.oxfam.org.au/wp-content/uploads/2018/03/1-Oxfam-AidPolicyBrief-Nov2017.pdf

Oxfam Australia. (2018). Submission to the Senate Inquiry into the United Nations Sustainable Development Goals (SDG). https://www.aph.gov.au

Palmer, D. J., Stephens, D., Fisher, D. A., Spain, B., Read, D. J., \& Notaras, L. (2003) 'The Bali bombing: the Royal Darwin Hospital response', The Medical Journal of Australia, 179(7) 358-361

Parry, D. (2012, October 5). The legacy of Darwin's response to the Bali bombings, $A B C$ https://www.abc.net.au/ news/2012-10-05/the-legacy-of-darwins-response-to-the-bali-bombings/4298814?nw=0

Paton, D, Johnston, D. (2017). Disaster Resilience: An integrated approach. (2 ${ }^{\text {nd }}$ Ed). Charles C Thomas Publisher Ltd Rechniewski, E. (2012). Forgetting and Remembering the Darwin Bombings. E-rea, 10(1) https://doi.org/10.4000/ erea.2861

Salleh, A. (2007, April 10). Global Warming Hits Indigenous People Most. ABC Science. https://www.abc.net.au/science/ articles/2007/04/10/1892812.htm

Save the Children. (2019). 2019-20 Pre-Budget Submission. https://treasury.gov.au/sites/default/files/2019-03/360985Save-the-Children-Australia.pdf

The South Australian Register. (1886, February 12). The alleged slaughter of blacks in the NT. https://trove.nla.gov.au/ newspaper/article/50184608

Ungunmerr-Baumann, M. (2019, December 9) Cultural Awareness Workshop, Nauiyu Community

Zara, C., Parkinson, D. (2013). Men on Black Saturday: Risks and opportunities for change. Women's Health Goulburn North East. https://www.genderanddisaster.com.au/wp-content/uploads/2015/O6/Doc-O11-Men-on-Black-SaturdayVols-1-and-2.pdf 